\title{
Ethnicity as a risk factor for obstructive sleep apnea: comparison of Japanese descendants and white males in São Paulo, Brazil
}

\author{
P.R. Genta, B.F. Marcondes, N.J. Danzi and G. Lorenzi-Filho \\ Laboratório do Sono, Serviço de Pneumologia, Instituto do Coração, Hospital das Clínicas, Faculdade de \\ Medicina, Universidade de São Paulo, São Paulo, SP, Brasil \\ Correspondence to: P.R. Genta, Laboratório do Sono, Serviço de Pneumologia, InCor, HC, FM-USP, \\ Av. Dr. Enéas C. Aguiar, 44, Sala 7079, 05403-000 São Paulo, SP, Brasil \\ Fax: +55-11-3069-5095. E-mail: prgenta@usp.br
}

\begin{abstract}
Some studies showed that Asians with obstructive sleep apnea (OSA) are thinner than Caucasians. Because obesity is a major risk factor for OSA, it was concluded that Asians are predisposed to OSA. However, body fat composition varies for a same body mass index (BMI) according to ethnicity. We firstly compared anthropometric characteristics, symptoms and associated disorders in all consecutive male Japanese descendants and white males with OSA referred for polysomnography. In a second analysis, all Japanese descendants were compared to a subgroup of white males, matched for apnea/hypopnea index and age. In the first analysis, age, symptoms, OSA severity and co-morbidities were similar among Japanese descendants $(\mathrm{N}=54)$ and white patients $(\mathrm{N}=466)$. However, Japanese descendants had a lower BMI than white patients: 27.1 (25.5-28.4) vs 29.4 (26.5$33.0) \mathrm{kg} / \mathrm{m}^{2}$, respectively $(P<0.001)$. In the second analysis, Japanese descendants had a lower BMI than white patients $(P<$ 0.001). Multiple linear regression considering the entire group revealed that age, BMI, neck circumference, Epworth sleepiness scale, ethnicity and \%REM sleep were independent predictors for apnea/hypopnea index $(P<0.001)$. Ethnicity was no longer significantly associated with OSA severity when we adopted the World Health Organization criteria for obesity ( $\geq 25$ and $30 \mathrm{~kg} /$ $\mathrm{m}^{2}$ among Japanese descendants and white males, respectively). Japanese descendants with OSA have a lower BMI than white subjects of similar severity. However, ethnicity was not associated with OSA severity when an ethnical difference in obesity criteria was respected. Our data suggest that Japanese descendants are not predisposed to OSA.
\end{abstract}

Key words: Asians; Obesity; Obstructive sleep apnea; Japanese; Ethnicity; Body mass index

Presented at the XI Congresso Brasileiro do Sono, Fortaleza, CE, Brazil, November 11-14, 2007.

Publication supported by FAPESP.

Received November 6, 2007. Accepted June 16, 2008

\section{Introduction}

Obstructive sleep apnea (OSA) is characterized by repetitive partial or complete obstruction of the upper airways during sleep. The susceptibility to collapse of the upper airways is determined by the interaction of several factors, including craniofacial morphology and ventilatory control (1). Obesity is a major risk factor for OSA, particularly when associated with central deposition of fat around the upper airways $(2,3)$. Specific ethnicities may represent a risk factor for OSA. For instance, African-Americans have been reported to be at increased risk for OSA when compared to Caucasians (4). A few recent studies have suggested a greater severity of OSA among Asians than among Caucasians, when subjects are matched for body mass index (BMI) $(5,6)$. Conversely, it has also been shown that among OSA patients of similar disease severity, Asians were less obese than Caucasians (5-7). Taken together, the data suggest that Asians may be predisposed to developing OSA. 
The mechanisms for an increased OSA severity in Asians as compared to Caucasians, when matched for $\mathrm{BMI}$, are not completely understood. It is possible that Asians have craniofacial characteristics that would render the upper airways more prone to collapse. Another factor that may also play a role is that Asians have a higher percentage of body fat when compared to Caucasians of the same BMI and age (8). This finding may help explain the higher frequency of associated disorders such as type 2 diabetes at lower BMls found in Asians compared to Caucasians (9). These data led the World Health Organization (WHO) and the Japanese Society for the Study of Obesity to recently propose a BMI of $25 \mathrm{~kg} / \mathrm{m}^{2}$ or higher to define obesity in the Asian population as opposed to $30 \mathrm{~kg} /$ $\mathrm{m}^{2}$ or higher in Caucasians $(10,11)$.

São Paulo, Brazil, is a city with the largest community of Japanese descendants outside Japan. The first Japanese immigrants came to Brazil in the first decade of the last century. This provides the possibility to study a single population of Asians, as opposed to previous studies that pooled together different Asian ethnicities (5-7). The purpose of the present study was to compare differences between Japanese descendants and white patients with OSA referred to a single sleep laboratory. We hypothesized that Japanese descendants referred to the sleep laboratory would have a lower BMI despite a similar OSA severity when compared to white patients.

\section{Subjects and Methods}

All Japanese descendants and all white patients who underwent polysomnography at the Sleep Laboratory, Pulmonary Division, Heart Institute, University of São Paulo, from 2002 to 2006, were included in this retrospective study. Japanese descendants and white subjects were compared in two different analysis: 1) all consecutive patients that fulfilled inclusion criteria during the study period, and 2) Japanese descendants and white subjects matched for apnea/hypopnea index $(\mathrm{AHI})$ and age at a proportion of 1 Japanese descendant to 2 white patients. Maximum differences of 2 events $/ \mathrm{h}$ for $\mathrm{AHI}, 1 \mathrm{~kg} / \mathrm{m}^{2}$ for BMI and 3 years for age were used for matching.

We excluded patients younger than 18 years, patients participating in continuous positive airway pressure titration studies, and patients participating in study protocols. We also excluded African descendants, Mulattos and Asian descendants other than Japanese as well as those who were Japanese descendants but had a history of interethnic marriage within the last three generations. Due to the small number of Asian descendant women, the study included only males.
Ethnicity was determined from the self-reported information obtained at the time of the sleep study. Japanese descendants were questioned whether their grandparents, parents or themselves were Japanese natives. History was obtained on the night of the sleep study and included: educational level, daytime somnolence as determined by the Epworth sleepiness scale (ESS) (12), presence of snoring, smoking habit and associated disorders including hypertension, diabetes mellitus, congestive heart failure, and ischemic heart disease. Weight, height and neck circumference were determined on the night of the sleep study. Because taller people are expected to have larger necks, we also calculated the neck/height ratio (13). We also defined obesity according to ethnicity using the $\mathrm{WHO}$ and Japanese criteria (BMI greater than 25 and 30 $\mathrm{kg} / \mathrm{m}^{2}$ for Japanese descendants and for white patients, respectively) $(10,11)$.

The polysomnography studies included electroencephalography, eletrooculography, chin and leg electromyography, and electrocardiography, oximetry, measurements of airflow with a nasal pressure cannula, and measurements of ribcage and abdominal movements during breathing (Alice 4; Respironics Inc., USA). All studies were manually scored. Apnea was defined as complete cessation of airflow for at least $10 \mathrm{~s}$. Hypopnea was defined as a reduction in respiratory signals for at least $10 \mathrm{~s}$ associated with oxygen desaturation of $\geq 3 \%$ or arousal. The AHI was calculated as the total number of respiratory events (apneas plus hypopneas) per hour of sleep. An AHI $\geq 5$ events/ $h$ was used to define OSA.

Japanese descendants and white patients were compared using the unpaired Student $t$-test and the MannWhitney U-test for non-normally distributed continuous variables. The $Z$ test was used for comparison of proportions. Multiple linear regressions were used to identify variables that made an important contribution to the variability of the apnea/hypopnea events during sleep in the entire study group. To this end, AHI was considered to be the dependent variable, whereas age, ethnicity, BMI, neck circumference, ESS score and \%REM sleep were considered to be independent variables. Multiple linear regression was also performed, replacing BMI with obesity (taking into account ethnicity, as previously described) and neck circumference with neck/height ratio. AHI was logarithmically transformed for multiple linear regression analysis due to its non-normal distribution. The study was approved by the local Ethics Committee.

\section{Results}

During the study period, 586 patients of the 2290 sleep 
studies fulfilled the inclusion criteria. Subjects who participated in study protocols $(\mathrm{N}=1228)$ or in continuous positive airway pressure titration studies $(\mathrm{N}=100)$, women $(\mathrm{N}=303)$, other ethnicities $(\mathrm{N}=70)$ and Japanese descendants mixed with other races $(N=5)$ were excluded. Among the 586 patients included, 61 were Japanese descendants. The proportion of individuals with OSA was similar among white patients and Japanese descendants (89 and $88 \%$, respectively). Therefore, the patients with diagnostic criteria for OSA included for further analysis consisted of 54 Japanese descendants and 466 white patients. Of the 54 Japanese descendants, 67\% were sons and $27 \%$ were grandsons of Japanese natives. The other $6 \%$ were Japanese natives. Japanese descendants and white OSA patients were similar with respect to age, educational level, symptoms, and associated disorders

Table 1. Demographic data, symptoms, associated disorders and polysomnography data of consecutive Japanese descendants and white patients.

\begin{tabular}{|c|c|c|}
\hline & $\begin{array}{c}\text { Japanese descendants } \\
\qquad(\mathrm{N}=54)\end{array}$ & $\begin{array}{l}\text { White patients } \\
\qquad(\mathrm{N}=466)\end{array}$ \\
\hline \multicolumn{3}{|l|}{ Demographic data } \\
\hline Age (years) & $53.3 \pm 12.6$ & $50.6 \pm 13.6$ \\
\hline Education $>12$ th grade $(\%)$ & 66 & 67 \\
\hline BMI $\left(\mathrm{kg} / \mathrm{m}^{2}\right)$ & $27.1(25.5-28.4)$ & $29.4(26.5-33.0)^{* *}$ \\
\hline Obesity (\%) & 80 & $44^{* *}$ \\
\hline Height $(\mathrm{cm})$ & $166 \pm 6.2$ & $173 \pm 7.4^{\star \star}$ \\
\hline Neck circumference $(\mathrm{cm})$ & $40(38-42)$ & $42(39.5-44)^{\star \star}$ \\
\hline Neck/height ratio & $0.24(0.23-0.25)$ & $0.24(0.23-0.25)$ \\
\hline \multicolumn{3}{|l|}{ Polysomnography } \\
\hline Total sleep time (min) & $392(339-440)$ & $366(315-405)^{\star}$ \\
\hline Sleep efficiency (\%) & $88.8(74.1-93.5)$ & $87.3(77.3-93.8)$ \\
\hline S1 (\%) & $5(2.7-10.7)$ & $4.5(2.1-8.5)$ \\
\hline S2 (\%) & $72.1(64.9-78)$ & $70.3(60.6-77.3)$ \\
\hline S3 (\%) & $3.6(1.1-6.2)$ & $3.7(1.3-6.5)$ \\
\hline S4 (\%) & $1.7(0-6.6)$ & $2.9(0-7.9)$ \\
\hline REM (\%) & $11.7 \pm 6.7$ & $14.2 \pm 7.6^{*}$ \\
\hline Arousals $(\mathrm{N})$ & $196(143-274)$ & $201(138-285)$ \\
\hline $\mathrm{AHI}$ (events/h) & $36.5(20.1-54.9)$ & $28.5(14.7-48.6)$ \\
\hline Lowest $\mathrm{SaO}_{2}(\%)$ & $80(75-85)$ & $82(74-86)$ \\
\hline \multicolumn{3}{|l|}{ Associated symptoms } \\
\hline Epworth sleepiness scale & $10(6-16)$ & $10(7-14)$ \\
\hline Snoring (\%) & 92 & 96 \\
\hline \multicolumn{3}{|l|}{ Associated disorders } \\
\hline Hypertension (\%) & 55 & 43 \\
\hline Diabetes (\%) & 16 & 8 \\
\hline Smoking (\%) & 20 & 13 \\
\hline Ischemic heart disease (\%) & 7 & 5 \\
\hline Congestive heart failure (\%) & 13 & 6 \\
\hline
\end{tabular}

Data are reported as mean $\pm S D$, median (interquartile range) or as otherwise stated. $\mathrm{BMI}=$ body mass index; $\mathrm{S} 1-\mathrm{S} 4$ = sleep stages; $\mathrm{REM}=$ rapid eye movement; $\mathrm{AHI}=$ apnea-hypopnea index; $\mathrm{SaO}_{2}=$ oxygen saturation .

${ }^{*} \mathrm{P} \leq 0.05$ compared to Japanese descendants ( $t$-test and Mann-Whitney U-test, where appropriate). ${ }^{* *} P \leq 0.001$ compared to Japanese descendants ( $t$-test, Mann-Whitney U-test and Z test, where appropriate).
(Table 1). The AHI was similar in Japanese descendants and white patients. In accordance with previous studies, Japanese descendants presented a lower BMI (5-7). However, we extended the previous findings by showing that such difference must be interpreted in the context that the two ethnicities are markedly different in several aspects. Japanese descendants were shorter, thinner and presented a smaller neck circumference than white patients. For instance, when corrected for height (13), neck circumference was similar in the two ethnic groups. Moreover, the prevalence of obesity, when the WHO and Japanese definition for obesity was taken into account, was not lower, but significantly greater among Japanese descendants than among white patients (Table 1).

The second analysis conveyed similar information. When Japanese descendants $(N=54)$ were matched with white subjects $(\mathrm{N}=108)$ for $\mathrm{AHI}$ and age (Table 2), Japanese descendants had a lower BMI compared to non-Asians but a higher prevalence of obesity.

Multiple linear regression was used to identify variables that made an important contribution to the variability of AHI. Age, BMI, neck circumference, ESS, \%REM sleep and ethnicity were independently associated with AHI (P<0.001; Table 3). Taking into account the different anthropometric characteristics of each ethnic group, we replaced BMI and neck circumference with obesity and neck/height ratio. In this model, ethnicity was no longer significantly associated with $\mathrm{AHI}(\mathrm{P}=0.37$; Table 4).

\section{Discussion}

Our results agree with recent studies and show that Japanese descendants with OSA referred to a sleep laboratory have a similar AHI but a significantly lower BMI than white patients $(5,7)$. Studies that controlled for BMI conveyed a similar message, and showed a higher $\mathrm{AHI}$ in Asians compared to Caucasians $(6,7)$. Likewise, our multiple linear regression model, that controlled for BMI and neck circumference, showed that being a Japanese descendant was associated with increased AHI. Therefore, Japanese descendant males are predisposed to OSA even though they are not obese according to the standard for Caucasians. Our data suggest that the usual crite- 
rion for obesity $\left(30 \mathrm{~kg} / \mathrm{m}^{2}\right)$ is misleading when the risk for OSA is assessed among Japanese descendants.

Our findings that age, BMI, neck circumference and ESS were associated with $\mathrm{AHI}$ are in accordance with large epidemiological studies (2,13-17). Neck circumference is considered to be a surrogate measure of upper airway fat and, in addition to BMI, is a sensitive predictor of OSA $(13,17)$. Accordingly, BMI and neck circumference were the two factors most frequently associated with $\mathrm{AHI}$ in our multiple linear regression model. The mechanisms that link obesity to OSA are not completely understood. Upper body obesity and fat deposition around the upper airways are major risk factors for OSA. This may help explain, for

Table 2. Demographic data, polysomnography and sleepiness data of Japanese descendants and white patients matched for $\mathrm{AHI}$ and age.

\begin{tabular}{lll}
\hline & $\begin{array}{c}\text { Japanese descendants } \\
(\mathrm{N}=54)\end{array}$ & \multicolumn{1}{c}{$\begin{array}{c}\text { White patients } \\
(\mathrm{N}=108)\end{array}$} \\
\hline $\begin{array}{l}\text { Demographic data } \\
\text { Age (years) }\end{array}$ & $53.3 \pm 12.6$ & $52.9 \pm 11.6$ \\
BMI (kg/m $\left.{ }^{2}\right)$ & $27.1(25.5-28.4)$ & $29.3(26.5-33.6)^{*}$ \\
Obesity $(\%)$ & 80 & $43^{*}$ \\
Height $(\mathrm{cm})$ & $166 \pm 6.2$ & $173 \pm 7.4^{*}$ \\
Neck circumference $(\mathrm{cm})$ & $39.7 \pm 3.4$ & $42.7 \pm 3.4^{*}$ \\
Neck/height ratio & $0.24(0.23-0.25)$ & $0.24(0.23-0.26)$ \\
Polysomnography & & \\
AHI (events/h) & $36.5(20.1-54.9)$ & $35.7(19.4-53.8)$ \\
Lowest SaO 2 (\%) & $80(75-85)$ & $81(72-85)$ \\
Sleepiness & $11 \pm 6$ & $12 \pm 5$ \\
Epworth sleepiness scale & & \\
\hline
\end{tabular}

Data are reported as mean $\pm S D$, median (interquartile range) or as otherwise stated. $\mathrm{BMI}=$ body mass index; $\mathrm{AHI}=$ apnea-hypopnea index; $\mathrm{SaO}_{2}=$ oxygen saturation. Obesity was defined as $B M I \geq 25 \mathrm{~kg} / \mathrm{m}^{2}$ for Japanese descendants and $\geq 30 \mathrm{~kg} / \mathrm{m}^{2}$ for white patients.

${ }^{*} \mathrm{P} \leq 0.001$ compared to Japanese descendants ( $t$-test, Mann-Whitney U-test and $Z$ test, where appropriate). instance, the greater propensity to OSA among males compared to females (17). In agreement with this view, one study compared body fat composition between OSA patients and controls paired for BMI. The authors showed that OSA patients had a greater percentage of body fat (18). Despite an apparent smaller neck circumference among Japanese descendants in our study, the difference was no longer present when corrected for height (13). Likewise, the absolute BMI value may not convey sufficient information about fat deposition, particularly when different populations are compared. For instance, Wang et al. (8) compared the percentage of body fat and fat distribution between Caucasians and Chinese descendants living in New York City and observed that Asians had a lower BMI but a higher percentage of body fat and more upper-body subcutaneous fat than did whites. This concept was also acknowledged by the WHO (10) and by the Japanese Society for the Study of Obesity (11), that lowered the BMI cut-off for obesity among Asians from $\geq 30$ to $\geq 25 \mathrm{~kg} /$ $\mathrm{m}^{2}$. As a matter of fact, these criteria have been used in different studies from Japan and China (19-21). After adopting these criteria, the percentage of obesity was higher in the Japanese descendants than in white patients (Tables 1 and 2). Obesity among Japanese descendants may be explained in part by the acculturation process with modifications in life style and diet leading to an increase in weight. This was demonstrated among Japanese descendants living in Brazil compared to Japanese living in Japan (22).

According to our linear regression, model
Table 3. Multiple linear regression results considering $\operatorname{Ln}(\mathrm{AHI})$ as the dependent variable and BMI, age, neck circumference, Epworth sleepiness scale and \%REM as independent variables.

\begin{tabular}{lcr}
\hline Variable & $\mathrm{R}$ & \multicolumn{1}{c}{$\mathrm{P}$} \\
\hline BMI & 0.29 & 0.016 \\
Age & 0.07 & $<0.001$ \\
Neck circumference & 0.03 & $<0.001$ \\
Epworth sleepiness scale & 0.02 & 0.002 \\
Ethnicity & 0.03 & $<0.001$ \\
\%REM & 0.01 & 0.025 \\
Model & 0.45 & $<0.001$ \\
\hline
\end{tabular}

$\mathrm{BMI}=$ body mass index; $\mathrm{REM}=$ rapid eye movement.
Table 4. Multiple linear regression results after replacing body mass index (BMI) and neck circumference with obesity and neck/height ratio.

\begin{tabular}{llr}
\hline Variable & $\mathrm{R}$ & $\mathrm{P}$ \\
\hline Obesity & 0.29 & $<0.001$ \\
Age & 0.06 & $<0.001$ \\
Neck/height ratio & 0.02 & 0.007 \\
Epworth sleepiness scale & 0.01 & 0.004 \\
Ethnicity & 0.004 & 0.369 \\
REM & 0.01 & 0.007 \\
Model & 0.40 & $<0.001$ \\
\hline
\end{tabular}

Obesity was defined as BMI $\geq 25 \mathrm{~kg} / \mathrm{m}^{2}$ for Japanese descendants $(\mathrm{N}=54)$ and $\geq 30 \mathrm{~kg} / \mathrm{m}^{2}$ for white patients $(\mathrm{N}=466)$. REM $=$ rapid eye movement. 
being a Japanese descendant is a risk factor for OSA. The important message is that when evaluating the risk for OSA among Asians, a lower BMl cut-off should be employed. When we changed the definition of obesity among Japanese descendants to $25 \mathrm{~kg} / \mathrm{m}^{2}$ (according to the WHO and to Japanese criteria), being Asian was no longer associated with OSA severity. This model may help to reconcile data from large epidemiological studies that show a similar prevalence of OSA among different populations. For instance, Ip et al. (14) studied middle-aged Chinese workers in Hong Kong and found prevalence rates of $4.1 \%$ among men and $2.1 \%$ among women. Kim et al. (15) found a prevalence of OSA of $4.5 \%$ among middle-aged Korean men and $3.2 \%$ among women. More recently, similar prevalence rates among men $(4.9 \%)$ and women $(2.1 \%)$ were reported in India (16). These rates in different Asian ethnic groups are very similar to those published by Young et al. (2) who found a prevalence of $4 \%$ among middle-aged American men and $2 \%$ among women. The $\mathrm{WHO}$ and Japanese criteria, that in our study may help explain the propensity for OSA among Asians, were also very useful to explain the unexpected high prevalence of disorders associated with obesity such as type 2 diabetes in Asian populations (9).

Craniofacial differences between Asians and Caucasians have been proposed as a major explanatory mechanism that accounts for a greater tendency to OSA among Asians (1). The craniofacial structure is composed of bony and soft tissue components. Cephalometry identifies these structures and permits comparisons against published norms. The most common cephalometric abnormalities reported among OSA patients include an inferiorly positioned hyoid bone, a posteriorly placed maxilla and mandible, an enlarged tongue and soft palate, as well as a smaller velopharyngeal cross-sectional area (3). In this context, intra-ethnic studies among Caucasians and Asians have found similar cephalometric abnormalities in OSA patients and controls $(5,23)$. However, cephalometric characteristics comparing OSA patients of different ethnic groups are in fact controversial. There is evidence supporting the theory that Asians have an unfavorable anatomy. For instance, a shorter and steeper anterior cranial base angle, that may predispose to OSA, was observed among Asians with OSA compared to Caucasians $(5,24)$. On the other hand, a more inferiorly positioned hyoid bone and a decreased posterior airway space were described in Caucasians with OSA compared to Asians (5). The latter observation would lead to the opposite conclusion, i.e., Caucasians may be more prone to OSA. Therefore, although there may be differences in craniofacial structure between Asians and Caucasians, to date it is not possible to determine the magnitude of the risk conferred by these characteristics.

Differences in sleep architecture among different ethnicities are controversial $(25,26)$. In our study, REM sleep was significantly shorter in Japanese descendants than in white patients. These findings cannot be explained by the AHI, which was similar between ethnic groups. We observed a negative association between REM sleep and AHI ( $B$ coefficient -0.32), independent of ethnicity. Although it is well known that OSA is generally worse in REM sleep because of the associated muscle atony, a negative association between percentage of REM and $\mathrm{AHI}$ has been reported (26). One possible explanation for such apparently unexpected finding is that a higher $\mathrm{AHI}$ would lead to a reduction of REM sleep.

Our study has several limitations. We only studied patients referred to the sleep laboratory, and potential referral bias may have occurred. We acknowledge that $\mathrm{BMI}$ alone, although a good predictor of OSA, does not discriminate between body fat and lean mass. Although we raised the hypothesis that different BMI cut-offs may help explain the propensity to OSA among Asians, we did not determine body fat distribution and did not evaluate cephalometric parameters in our patients. An increase in symptom perception and a lower educational level have been proposed as possible explanations for the higher severity of OSA among Asians reported previously (6). However, we did not observe differences in symptoms (sleepiness, snoring and tiredness) or educational level between Japanese descendants and white patients. Previous studies that compared sleep characteristics between Asians and Caucasians included different Asian ethnicities (5-7). However, the prevalence of obesity and associated disorders varies among different Asian populations (9). In contrast, the present study only included a homogeneous population of non-mixed Japanese descendants.

We observed that Japanese descendants with OSA have a lower BMI but a similar AHI compared to white patients as previously described (5-7). However, ethnicity was not associated with OSA severity when an ethnical difference in obesity criteria was respected. This may indicate that Japanese descendants are not predisposed to OSA. Our observations suggest that the risk for OSA associated with obesity may be largely under-recognized among Japanese descendants. There may be a delay or under-diagnosis of OSA if a BMI $>30 \mathrm{~kg} / \mathrm{m}^{2}$ is considered to be the criterion for obesity in Japanese descendants. 


\section{References}

1. Villaneuva AT, Buchanan PR, Yee BJ, Grunstein RR. Ethnicity and obstructive sleep apnoea. Sleep Med Rev 2005; 9: 419-436.

2. Young T, Palta M, Dempsey J, Skatrud J, Weber S, Badr S. The occurrence of sleep-disordered breathing among middle-aged adults. N Engl J Med 1993; 328: 1230-1235.

3. Lam B, Ip MS, Tench E, Ryan CF. Craniofacial profile in Asian and white subjects with obstructive sleep apnoea. Thorax 2005; 60: 504-510.

4. Redline S, Tishler PV, Hans MG, Tosteson TD, Strohl KP, Spry K. Racial differences in sleep-disordered breathing in African-Americans and Caucasians. Am J Respir Crit Care Med 1997; 155: 186-192.

5. Li KK, Kushida C, Powell NB, Riley RW, Guilleminault C. Obstructive sleep apnea syndrome: a comparison between Far-East Asian and white men. Laryngoscope 2000; 110: 1689-1693.

6. Ong KC, Clerk AA. Comparison of the severity of sleepdisordered breathing in Asian and Caucasian patients seen at a sleep disorders center. Respir Med 1998; 92: 843-848.

7. Li KK, Powell NB, Kushida C, Riley RW, Adornato B, Guilleminault C. A comparison of Asian and white patients with obstructive sleep apnea syndrome. Laryngoscope 1999; 109: 1937-1940.

8. Wang J, Thornton JC, Russell M, Burastero S, Heymsfield $\mathrm{S}$, Pierson RN Jr. Asians have lower body mass index (BMI) but higher percent body fat than do whites: comparisons of anthropometric measurements. Am J Clin Nutr 1994; 60: 23-28.

9. Yoon $\mathrm{KH}$, Lee JH, Kim JW, Cho JH, Choi YH, Ko SH, et al. Epidemic obesity and type 2 diabetes in Asia. Lancet 2006; 368: $1681-1688$

10. World Health Organization. The Asia-pacific perspective: redefining obesity and its treatment. Health Communications, Australia 2000. WHO http://www.diabetes.com.au/ pdf/obesity_report.pdf; 2000.

11. Examination Committee of Criteria for 'Obesity Disease' in Japan, Japan Society for the Study of Obesity. New criteria for 'obesity disease' in Japan. Circ J 2006; 70: 150 (author reply).

12. Johns MW. A new method for measuring daytime sleepiness: the Epworth sleepiness scale. Sleep 1991; 14: 540545.

13. Davies RJ, Ali NJ, Stradling JR. Neck circumference and other clinical features in the diagnosis of the obstructive sleep apnoea syndrome. Thorax 1992; 47: 101-105.

14. Ip MS, Lam B, Lauder IJ, Tsang KW, Chung KF, Mok YW, et al. A community study of sleep-disordered breathing in middle-aged Chinese men in Hong Kong. Chest 2001; 119: 62-69.

15. Kim J, In K, Kim J, You S, Kang K, Shim J, et al. Prevalence of sleep-disordered breathing in middle-aged Korean men and women. Am J Respir Crit Care Med 2004; 170: 11081113.

16. Sharma SK, Kumpawat S, Banga A, Goel A. Prevalence and risk factors of obstructive sleep apnea syndrome in a population of Delhi, India. Chest 2006; 130: 149-156.

17. Dancey DR, Hanly PJ, Soong C, Lee B, Shepard J Jr, Hoffstein V. Gender differences in sleep apnea: the role of neck circumference. Chest 2003; 123: 1544-1550.

18. Mortimore IL, Marshall I, Wraith PK, Sellar RJ, Douglas NJ. Neck and total body fat deposition in nonobese and obese patients with sleep apnea compared with that in control subjects. Am J Respir Crit Care Med 1998; 157: 280-283.

19. Lam B, Ooi CG, Peh WC, Lauder I, Tsang KW, Lam WK, et al. Computed tomographic evaluation of the role of craniofacial and upper airway morphology in obstructive sleep apnea in Chinese. Respir Med 2004; 98: 301-307.

20. Chin K, Nakamura T, Takahashi K, Sumi K, Ogawa Y, Masuzaki $\mathrm{H}$, et al. Effects of obstructive sleep apnea syndrome on serum aminotransferase levels in obese patients. Am J Med 2003; 114: 370-376.

21. Lam JC, Lam B, Lam CL, Fong D, Wang JK, Tse HF, et al. Obstructive sleep apnea and the metabolic syndrome in community-based Chinese adults in Hong Kong. Respir Med 2006; 100: 980-987.

22. Schwingel A, Nakata Y, Ito LS, Chodzko-Zajko WJ, Erb CT, Shigematsu $R$, et al. Central obesity and health-related factors among middle-aged men: a comparison among native Japanese and Japanese-Brazilians residing in Brazil and Japan. J Physiol Anthropol 2007; 26: 339-347.

23. Sakakibara $H$, Tong $M$, Matsushita $K$, Hirata $M$, Konishi $Y$, Suetsugu S. Cephalometric abnormalities in non-obese and obese patients with obstructive sleep apnoea. Eur Respir $J$ 1999; 13: 403-410.

24. Liu Y, Lowe AA, Zeng X, Fu M, Fleetham JA. Cephalometric comparisons between Chinese and Caucasian patients with obstructive sleep apnea. Am J Orthod Dentofacial Orthop 2000; 117: 479-485.

25. Poland RE, Rao U, Lutchmansingh $P$, McCracken JT, Lesser IM, Edwards C, et al. REM sleep in depression is influenced by ethnicity. Psychiatry Res 1999; 88: 95-105.

26. Redline S, Kirchner HL, Quan SF, Gottlieb DJ, Kapur V, Newman A. The effects of age, sex, ethnicity, and sleepdisordered breathing on sleep architecture. Arch Intern Med 2004; 164: 406-418. 